\title{
How ACM Is Adapting in This Period of Global Uncertainties
}

\section{As the world continues its efforts to slow the COVID-19 pandemic, our daily lives and routines have changed dramatically. Companies have closed their physical}

locations and transitioned staff to working remotely, academic institutions-from primary school to universities-have sent students home and are turning exclusively to distance learning, and entire industries have scaled back in an effort to remain viable until the pandemic is contained. Both individually and collectively we are confronting personal, societal, and ethical dilemmas at a speed and scale few could foresee.

The global impact of computing and information technology has never been clearer than it is during this crisis. Real-time data sharing and computational modeling are central to efforts to analyze the spread of the virus, share public health strategies and experiences, and expedite development of new treatments and vaccines. At the same time, the use of social interaction platforms of all types has skyrocketed. That infrastructure is critical to keep families, friends, and colleagues connected, as well as to keep businesses, education, and government viable.

ACM's mission - to help unite the computing community, provide professional and technical information to those who need it, and advance the field-may be more relevant now than ever before. All of us at ACM are committed to continue supporting that mission throughout these difficult times. Here's an update on how ACM has responded to the crisis situation.

Like many other companies and non-profits, ACM has temporarily closed its New York City Headquarters and is functioning as a virtual organization, but all of our units are operating and will continue to do so. Of course, recognizing the need for social distancing, we have had to postpone a growing number of ACM meetings and conferences or transition them to virtual meetings. Our volunteers and conference leaders are having to make some very difficult decisions. Fortunately, ACM and its SIGs are financially prepared to weather the storm, and we are working actively to develop technical options and practical guidance to help conference organizers modify their plans.

Our publication activities continue unabated, with all magazines, journals, conference proceedings, books, and

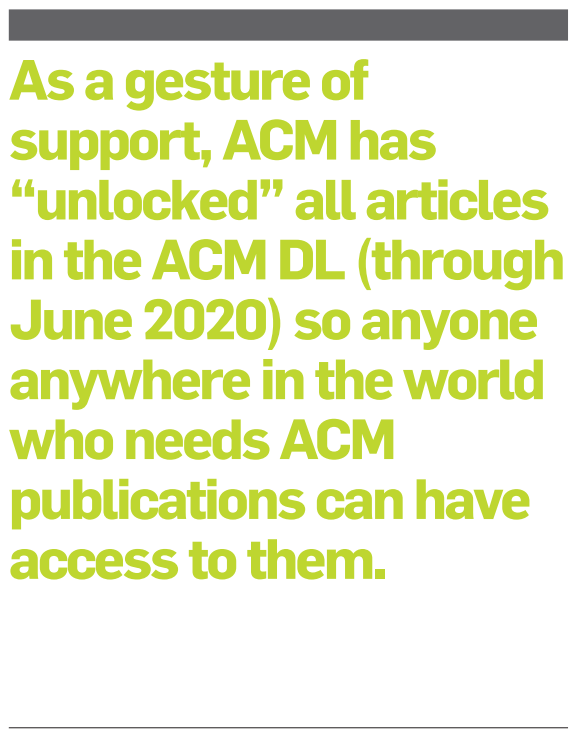

newsletters being released on schedule. That includes papers accepted for ACM conferences that have not been able to meet face-to-face. I should note this "business as usual" situation is only possible because of the dedicated efforts of our volunteers, who ensure editorial boards continue to function, peer review is taking place, and editors and program committees continue to make decisions that result in important articles being delivered to you.

As an added gesture of support for the entire computing profession, ACM leadership made the decision to "unlock" all articles in the ACM Digital Library starting at the end of March to ensure anyone anywhere in the world who needs ACM publications can have ready access. This policy will continue through June 30, 2020-so it might be a good time to catch up on some of that reading you have been intending to do.

ACM's members, volunteers, authors, and readers are at the center of everything we do. Your continued support and dedication during these difficult times are inspiring, and keep reminding us how very special our ACM community really is.

Hoping that all of you will remain healthy and safe,

\section{Cherri Pancake, ACM PRESIDENT}

Cherri M. Pancake is President of ACM, professor emeritus of electrical engineering and computer science, and director of a research center at Oregon State University, Corvallis, OR, USA.

Copyright held by author/owner. 